\title{
Novel Sources of Wheat Head Blast Resistance in Modern Breeding Lines and Wheat Wild Relatives
}

\author{
Giovana Cruppe, ${ }^{1, \dagger}$ Christian D. Cruz, ${ }^{2}$ Gary Peterson, ${ }^{3}$ Kerry Pedley, ${ }^{3}$ Mohammad Asif,,${ }^{4,5}$ Allan Fritz, ${ }^{5}$ Lidia Calderon, ${ }^{6}$ \\ Cristiano Lemes da Silva, ${ }^{7}$ Tim Todd, ${ }^{1}$ Paulo Kuhnem, ${ }^{8}$ Pawan K. Singh, ${ }^{9}$ Ravi P. Singh, ${ }^{9}$ Hans-Joachim Braun, \\ Naresh C. D. Barma, ${ }^{10}$ and Barbara Valent ${ }^{1}$ \\ ${ }^{1}$ Department of Plant Pathology, Kansas State University, Manhattan, KS 66506, U.S.A. \\ ${ }^{2}$ Department of Botany and Plant Pathology, Purdue University, West Lafayette, IN 47907, U.S.A. \\ ${ }^{3}$ United States Department of Agriculture-Agricultural Research Service, Foreign Disease-Weed Science Research Unit, Fort \\ Detrick, MD 21702, U.S.A. \\ ${ }^{4}$ Heartland Plant Innovations, Manhattan, KS 66506, U.S.A. \\ ${ }^{5}$ Department of Agronomy, Kansas State University, Manhattan, KS 66506, U.S.A. \\ ${ }^{6}$ Asociacion de Productores de Oleaginosas y Trigo, Santa Cruz de la Sierra, Bolivia \\ ${ }^{7}$ Corteva Agriscience, Windfall, IN 46076, U.S.A. \\ ${ }^{8}$ Biotrigo Genetica, Passo Fundo, Rio Grande do Sul 99052, Brazil \\ ${ }^{9}$ International Maize and Wheat Improvement Center, El Batan, Texcoco 56237, Mexico \\ ${ }^{10}$ Bangladesh Wheat and Maize Research Institute, Dinajpur 5200, Bangladesh
}

\begin{abstract}
Wheat head blast (WHB), caused by the fungus Magnaporthe oryzae pathotype triticum, is a devastating disease affecting South America and South Asia. Despite 30 years of intensive effort, the $2 \mathrm{~N}^{\mathrm{V}} \mathrm{S}$ translocation from Aegilops ventricosa contains the only useful source of resistance to WHB effective against $M$. oryzae triticum isolates. The objective of this study was to identify non- $2 \mathrm{~N}^{\mathrm{V}} \mathrm{S}$ sources of resistance to WHB among elite cultivars, breeding lines, landraces, and wild-relative accessions. Over 780 accessions were evaluated under field and greenhouse conditions in Bolivia, greenhouse conditions in Brazil, and at two biosafety level-3 laboratories in the United States. The M. oryzae triticum isolates B-71 (2012), 008 (2015), and 16MoT001 (2016) were used for controlled experiments, while isolate 008 was used for field experiments. Resistant and susceptible checks were included in all experiments. Under field conditions, susceptible spreaders were inoculated at the tillering stage to guarantee sufficient

diseased spikelets. The diagnostic marker Ventriup-LN2 was used to test for the presence of the $2 \mathrm{~N}^{\mathrm{V}} \mathrm{S}$ translocation. Four non- $2 \mathrm{~N}^{\mathrm{V}} \mathrm{S}$ spring wheat International Maize and Wheat Improvement Center breeding lines (CM22, CM49, CM52, and CM61) and four wheat wild-relatives (A. tauschii TA10142, TA1624, TA1667, and TA10140) were identified as resistant $(<5 \%$ of severity) or moderately resistant ( 5 to $<25 \%$ severity) to WHB. Experiments conducted at the seedling stage showed little correlation with disease severity at the head stage. $M$. oryzae triticum isolate $16 \mathrm{MoT} 001$ was significantly more aggressive against $2 \mathrm{~N}^{\mathrm{V}} \mathrm{S}$-based varieties. The low frequency of WHB resistance and the increase in aggressiveness of newer $M$. oryzae triticum isolates highlight the threat that the disease poses to wheat production worldwide and the urgent need to identify and characterize new resistance genes that can be used in breeding for durably resistant varieties.
\end{abstract} inoculum. Disease incidence and severity were evaluated as the average rating for each 1-m-row plot. Under controlled conditions, heads were inoculated after full emergence and individually rated for percentage of
Keywords: $2 \mathrm{~N}^{\mathrm{V}} \mathrm{S}$ translocation, genetic resistance, Magnaporthe oryzae triticum, wheat head blast
${ }^{\dagger}$ Corresponding author: G. Cruppe; gicruppe@ @ssu.edu

Mention of trade names or commercial products in this publication is solely for the purpose of providing specific information and does not imply recommendation or endorsement by the U.S. Department of Agriculture. USDA is an equal opportunity provider and employer.

Contribution number 19-303-J from the Kansas Agricultural Experiment Station.

Funding: This project is supported by Agriculture and Food Research Initiative Competitive Grant number 2013-68004-20378 from the United States Department of Agriculture (USDA) National Institute of Food and Agriculture. This research was partially financed by USDA Agricultural Research Service Projects 8044-220000-046-00D and 8044-2299-046-06R in addition to United States Agency for International Development (USAID) Agreement 021-022310-004-96-R. International Maize and Wheat Improvement Center (CIMMYT) wheat blast research activities were funded by the Australian Centre for International Agricultural Research (ACIAR), Indian Council of Agricultural Research (ICAR), USAID, and CRP WHEAT.

*The $\boldsymbol{e}$-Xtra logo stands for "electronic extra" and indicates that one supplementary figure and five supplementary tables are published online.

The author(s) declare no conflict of interest.

Accepted for publication 9 August 2019.

(C) 2020 The American Phytopathological Society
Wheat blast, currently a significant threat to wheat (Triticum aestivum L.) production, is caused by a specific subpopulation of the fungus Magnaporthe oryzae (T. T. Hebert) M. E. Barr (synonym of Pyricularia oryzae) (Couch and Kohn 2002; Zhang et al. 2016); specifically, the Triticum lineage or pathotype $M$. oryzae triticum (Gladieux et al. 2018; Murakami et al. 2000). For three decades, the disease was restricted to South America (Barea and Toledo 1996; Perelló et al. 2015; Viedma 2005); however, in 2016, the disease spread to Bangladesh, causing significant yield losses and decreasing the wheat area planted in subsequent seasons (Malaker et al. 2016; Mottaleb et al. 2019). Wheat blast epidemics are highly dependent upon environmental conditions such as warm temperatures $\left(25\right.$ to $\left.30^{\circ} \mathrm{C}\right)$, moisture (i.e., spike wetness between 25 and 40 h), and high relative humidity (>90\%) (Cardoso et al. 2008). Consequently, there is a high year-to-year variability in the magnitude of yield and quality losses due to the disease. In addition, cultivar susceptibility and timing of infection also influence wheat blast severity and potential damage to the crop (Goulart et al. 2007; Urashima et al. 2009). Wheat blast can be partially controlled by foliar fungicides (Goulart et al. 2007; Urashima et al. 2009); however, fungicides add an extra cost to wheat production and the benefits and efficacy are inconsistent. Previous studies have shown that foliar fungicides and other management practices such as fungicide seed treatments and delays in sowing date only provide proper wheat blast control under low to medium disease pressure, or when resistant cultivars are 
grown (Coelho et al. 2016; Cruz et al. 2015; Kohli et al. 2011; Mehta et al. 1992). Thus, the use of resistant cultivars is the most sustainable and effective option to control wheat blast.

Genetic resistance to wheat head blast (WHB), the most common form of the disease in the field, has relied upon a single source (i.e., the $2 \mathrm{~N}^{\mathrm{V}} \mathrm{S}$ translocation) (Cruz et al. 2016). This translocation was first introgressed into the wheat variety VPM1 (Bariana and McIntosh 1993; Jahier et al. 2001) from the wild relative Aegilops ventricosa. Varieties with the $2 \mathrm{~N}^{\mathrm{V}} \mathrm{S}$ translocation have been widely used in wheat breeding programs as a valuable source of resistance to some races of wheat leaf rust (caused by Puccinia triticina), stem rust (caused by $P$. graminis f. sp. tritici), and stripe rust (caused by $P$. striiformis f. sp. tritici) (Helguera et al. 2003). In addition, this translocation contains resistance $(R)$ genes to some pathotypes of the cereal cyst nematode (Heterodera avenae) and the root-knot nematode (Meloidogyne spp.) (Jahier et al. 2001; Williamson et al. 2013). Conveniently, no wheat grain yield penalty has been associated with the $2 \mathrm{~N}^{\mathrm{V}} \mathrm{S}$ translocation (Williamson et al. 2013).

Multiple varieties with $2 \mathrm{~N}^{\mathrm{V}} \mathrm{S}$-based resistance are currently used by wheat producers in South American countries and, more recently, in Bangladesh as the primary source for wheat blast control. Previous research showing variability in disease severity among $2 \mathrm{~N}^{\mathrm{V}} \mathrm{S}$-based varieties suggests that the genetic background or environment may influence the levels of resistance expression (Cruz et al. 2016). In addition, the strong isolate-cultivar interaction (Cruz et al. 2016; Maciel et al. 2014; Urashima et al. 2004) may influence this variability in disease severity. Consequently, relying solely on $2 \mathrm{~N}^{\mathrm{V}} \mathrm{S}$-based varieties as the foundation in breeding programs for wheat blast resistance is not recommended (Cruz and Valent 2017). Moreover, the durability of this source of resistance is unclear, especially with the possible emergence of more aggressive $M$. oryzae triticum races. In addition to the $2 \mathrm{~N}^{\mathrm{V}} \mathrm{S}$ translocation, five wheat $R$ genes ( $R m g 2$, $R m g 3$, Rmg7, Rmg8, and RmgGR119) have been identified as effective against some $M$. oryzae triticum strains (Anh et al. 2015; Tagle et al. 2015; Wang et al. 2018). However, the effectiveness of the majority of these genes ( $R m g 2$, $R m g 3$, and $R m g 7$ ) was significantly reduced by (i) temperatures higher than $26^{\circ} \mathrm{C}$, (ii) newer and more aggressive $M$. oryzae triticum races, and (iii) infection at the head stage and under field conditions. Anh et al. (2018) revealed that genes Rmg7, located on chromosome 2A in tetraploid wheat, and $R m g 8$, located on 2B in hexaploid wheat, do not share the same temperature sensitivity (i.e., $R m g 8$ was still effective under temperatures higher than $26^{\circ} \mathrm{C}$ ); however, both of these genes recognize the same avirulence $(A V R)$ gene, $A V R-R M G 8$. Wang et al. (2018) demonstrated that there is an additive effect (i.e., enhancement of disease resistance) when combining the genes Rmg8 and RmgGR119; however, this still needs to be evaluated under field conditions and against newer $M$. oryzae triticum isolates.

Table 1. Magnaporthe oryzae triticum race designation and reaction of a set of differential cultivars tested against the three $M$. oryzae triticum isolates used under controlled-environment experiments

\begin{tabular}{|c|c|c|c|c|}
\hline & & \multicolumn{3}{|c|}{ Cultivarw } \\
\hline \multicolumn{2}{|c|}{ M. oryzae triticum } & \multirow{2}{*}{$\begin{array}{c}\text { Everest } \\
\text { (non- } \\
\text { 2NvSS) }\end{array}$} & \multirow{2}{*}{$\begin{array}{c}\text { Jagalene } \\
\text { (2NvS) }\end{array}$} & \multirow{2}{*}{$\begin{array}{l}\text { RonL } \\
\text { (non- } \\
2 N^{v} \mathrm{~S} \text { ) }\end{array}$} \\
\hline $\operatorname{Race}^{x}$ & Isolate $^{y}$ & & & \\
\hline & & \multicolumn{3}{|c|}{ Race identification } \\
\hline 0 & $\ldots$ & $\mathrm{R}$ & $\mathrm{R}$ & $\mathrm{R}$ \\
\hline 1 & $\ldots$ & $\mathrm{S}$ & $\mathrm{R}$ & $\mathrm{R}$ \\
\hline 2 & $\ldots$ & $\mathrm{S}$ & $\mathrm{R}$ & $\mathrm{S}$ \\
\hline \multirow[t]{2}{*}{3} & $\ldots$ & S & S & S \\
\hline & & \multicolumn{3}{|c|}{ WHB severity $(\%)^{\mathrm{z}}$} \\
\hline 2 & B-71 & $88 \mathrm{a}$ & $13 \mathrm{a}$ & $94 \mathrm{a}$ \\
\hline 2 & 008 & $90 \mathrm{a}$ & $29 \mathrm{a}$ & $85 \mathrm{a}$ \\
\hline 2 & 16МoT001 & $89 \mathrm{a}$ & $38 \mathrm{~b}$ & $83 \mathrm{a}$ \\
\hline
\end{tabular}

${ }^{\mathrm{w}} \mathrm{R}=$ resistant and $\mathrm{S}=$ susceptible. Means followed by the same letter within

the same cultivar are not statistically different at $\alpha=0.05$.

$x$ Based on Cruz et al. (2016).

y M. oryzae triticum isolates used in this study.

$\mathrm{z}$ Wheat head blast (WHB) data collected in this study.
The effect of chemical and cultural recommendations to control wheat blast is inconsistent (Cruz et al. 2018) and the probability of a profitable operation for wheat producers is uncertain. Within this scenario, host plant resistance arises as one of the most promising strategies to mitigate wheat blast. Considering the significant variability of the $2 \mathrm{~N}^{\mathrm{V}} \mathrm{S}$-based resistance, the breakdown of some $R$ genes by newer and more aggressive isolates, and the inconsistency of cultural practices in controlling the disease, it is imperative to identify and deploy novel sources of resistance to wheat blast. New and unique sources can enhance the current genetic base for resistance, providing valuable new $R$ genes for wheat breeding programs. Therefore, our objective was to identify non- $2 \mathrm{~N}^{\mathrm{V}} \mathrm{S}$ sources of resistance to wheat blast among elite cultivars, breeding lines, landraces, and wheat wild-relative accessions.

\section{Materials and Methods}

Plant materials. In total, 780 wheat accessions, including spring and winter elite cultivars, modern breeding lines, landraces from a Nested Association Mapping (NAM) panel, cultivated emmer ( $T$. turgidum subsp. dicoccum), and A. tauschii (TA) accessions, were phenotyped for WHB resistance either in biosafety level-3 laboratories in the United States, under field and greenhouse conditions in Bolivia, or under greenhouse conditions in Brazil. The wheat accessions were genotyped for the presence of the $2 \mathrm{~N}^{\mathrm{V}} \mathrm{S}$ chromosome segment. A few selected non- $2 \mathrm{~N}^{\mathrm{V}} \mathrm{S}$ resistant and moderately resistant materials were further evaluated at the seedling stage (three-leaf stage) under controlled environments. It is uncertain whether the resistance at the head and at the leaf stages are controlled by the same $R$ genes.

The spring and winter wheat cultivars encompassed diverse sets of Bolivian, Brazilian, and North American elite cultivars that were selected based on four factors: i) high levels of wheat blast resistance reported in previous experiments using an older and less aggressive blast isolate (i.e., M. oryzae triticum isolate T-25) (Cruz et al. 2016), ii) superior yield and quality performance based on regional variety performance tests, iii) Bolivian and Brazilian cultivars that were widely grown in the blast-affected geography, and iv) cultivars that carry $R$ genes for other major fungal diseases such as Fusarium head blight, leaf rust, and stripe rust. The breeding lines tested in this study included spring breeding lines from Biotrigo Genetica and International Maize and Wheat Improvement Center (CIMMYT) breeding programs. The NAM (Yu et al. 2008) landraces were chosen to represent a diverse panel of geographic distribution of wheat across the globe, including accessions from 32 different countries. The emmer wheat entries were part of a collection derived from the National Small Grains Collection, United States Department of Agriculture (USDA) Agricultural Research Service (ARS), Aberdeen, ID, U.S.A. The TA entries were part of a minicore collection that included entries from 15 different countries and were selected based on preliminary studies using the T-25 M. oryzae triticum isolate (Cruz et al. 2016).

Production of inoculum, inoculation procedure, and disease ratings. Highly aggressive monosporic isolates were used in all experiments. Isolate B-71, collected in Okinawa (Bolivia) in 2012, was used for experiments conducted in the United States; isolate 008, collected in Quirusillas (Bolivia) in 2015, was used for experiments conducted in Bolivia; and isolate 16MoT001, collected in Passo Fundo, RS (Brazil) in 2016, was used for experiments conducted in Brazil. The three winter wheat cultivars Jagalene $\left(2 \mathrm{~N}^{\mathrm{V}} \mathrm{S}\right.$-based), RonL, and Everest, which do not carry the $2 \mathrm{~N}^{\mathrm{V}} \mathrm{S}$ translocation, were previously selected as the standard set of winter wheat differentials for $M$. oryzae triticum race identification (Cruz et al. 2012, 2016) and were used to characterize the aggressiveness of the isolates used in this study (Table 1). Cruz et al. (2012) and Cruz et al. (2016) demonstrated that the same cultivars had substantial differences in disease severity when tested against different isolates, which led to the designation of three different $M$. oryzae triticum races (namely, 0, 1, and 2). Within the current set of winter wheat differentials, Everest is highly susceptible to both races 1 and 2, RonL is resistant to race 1 but susceptible to race 2, and Jagalene is resistant to 
both races 1 and 2. M. oryzae triticum race 0 does not cause disease in any of the three cultivars; thus, it is not considered a wheat pathogen (Table 1). These cultivars were chosen due to their contrasting reactions with different isolates. All isolates used in this study were identified as race 2, based on reactions on this differential set (i.e., Everest and RonL were grouped as susceptible and Jagalene was grouped as resistant to intermediate) (Table 1). Although there was a significant difference in Jagalene's reaction when tested against the Brazilian isolate 16MoT001 compared with the other two isolates, we are still cautiously classifying this isolate as race 2. M. oryzae triticum isolates used in the United States were transported to a biosafety level-3 laboratory under the requirements stipulated by the USDA Animal and Plant Health Inspection Service.

Inoculum production, inoculation procedure, and disease rating followed protocols previously described by Cruz et al. (2016). $M$. oryzae triticum cultures were grown on homemade oatmeal agar (Valent et al. 1991) and, when sporulating cultures were 8 days old, they were flooded with a mixture of sterile deionized water with $0.42 \%$ unflavored gelatin and $0.01 \%$ Tween 20 , stirred to dislodge conidia from conidiophores, and filtered with four layers of sterile cheesecloth to eliminate the mycelia and any remaining agar medium. The spore concentration was adjusted to 20,000 spores $\mathrm{ml}^{-1}$ of suspension. For experiments conducted in controlled environments (i.e., greenhouse and growth chamber), $0.75 \mathrm{ml}$ of the spore suspension was individually applied to each wheat head approximately 2 days after full head emergence (Feekes GS 10.5) (Large 1954) using an airbrush (model 69492; Harbor Freight Tools, Camarillo, CA, U.S.A.). To provide the optimal conditions for $M$. oryzae triticum infection, the heads were covered with black plastic bags (model S-12322BL; ULINE) moistened with water for $48 \mathrm{~h}$ immediately following spore suspension application. Disease severity was evaluated every other day, starting at 8 until 14 days after inoculation, where each head was individually rated for the percentage of spikelets affected in a 0-to-100\% scale (Cruz et al. 2016). Susceptible and resistant checks were included in all experiments and varied according to country, seed availability, and experiment objective (e.g., spring versus winter). Disease severity was assessed on multiple days to characterize disease progress. However for statistical purposes, we used the data collected when the susceptible check reached $90 \%$ or more of disease severity (i.e., usually between 12 and 14 days after inoculation) (Cruz et al. 2016).

Field experiments. Irrigated field experiments were conducted during the 2017 and 2018 wheat growing seasons for a total of five location-years in Bolivia. Field experiments within each locationyear were grouped according to wheat classification (e.g., winter versus spring, different breeding programs, and so on), with a total of 12 individual experiments (Table 2). The locations selected are considered "hotspots" for wheat blast development because warm and moist conditions typically occur around wheat heading. In addition, two wheat-growing seasons per year in Bolivia facilitated data collection within a relatively short period. The two growing seasons were (i) South American winter (April to August) and (ii) South American summer (December to March). In the summer seasons of 2017 and 2018, the experiment was conducted at one location at a farmer's field near Quirusillas (18 $\left.{ }^{\circ} 19^{\prime} 45.92^{\prime \prime} \mathrm{S}, 63^{\circ} 56^{\prime} 51.44^{\prime \prime} \mathrm{W}\right)$. In the winter season of 2017, the experiment was conducted at two locations: the Association of Producers of Oilseeds and Wheat (ANAPO) Research Station near 26 de Agosto (17 $26^{\prime} 29.44^{\prime \prime} \mathrm{S}$, $\left.62^{\circ} 36^{\prime} 27.99^{\prime \prime} \mathrm{W}\right)$ and the Integral Cooperative Agricultural Colonies (CAICO) Research Station near Okinawa (17 ${ }^{\circ} 14^{\prime} 33.83^{\prime \prime}$ S, 62 $53^{\prime}$ $\left.21.41^{\prime \prime} \mathrm{W}\right)$. In the winter season of 2018 , the experiments were conducted at CAICO Research Station near Okinawa $\left(17^{\circ} 14^{\prime} 33.83^{\prime \prime} \mathrm{S}\right.$, $62^{\circ} 53^{\prime} 21.41^{\prime \prime} \mathrm{W}$ ).

For all experiments, $1-\mathrm{m}$-row plots with 20 -cm row spacing and planting density ranging from 60 (spring wheat entries) to 100 (winter wheat entries) seeds per linear meter were established in a randomized incomplete block design with three to six replications, depending on seed availability. Seed were treated with the fungicides carboxin $20 \%$ plus thiram $20 \%$ at a dose of $200 \mathrm{ml}$ per $100 \mathrm{~kg}$. To control weeds, fluroxypyr 1-methylheptyl ester [(4-amino-3, 5-dichloro-6-fluoro-2-pyridinyl)oxy]acetic acid, 1-methylheptyl ester] at 0.35 liter $\mathrm{ha}^{-1}$ and clodinafop propargil $\{[4-(5-$ cloro-3-fluropiridin-2-iloxi)fenoxi]propionate de prop-2-inilo $\}$ at 0.35 liter ha ${ }^{-1}$ were applied in all plots three times during the season. Insects were controlled by spraying benzoate at $0.6 \mathrm{~kg} \mathrm{ha}^{-1}$, split into three applications, and one application of thiametozan at $0.15 \mathrm{~kg}$ $\mathrm{ha}^{-1}$. Nitrogen was applied as urea split into two applications of $\mathrm{N}$ at $40 \mathrm{~kg} \mathrm{ha}^{-1}$ approximately at Feekes GS 2 (tillering initiation) and at Feekes GS 4 (leaf sheath lengthening). Each incomplete block consisted of six 1-m rows, where the outside rows were either a resistant or a susceptible check, and the four inside rows were candidate materials being evaluated. The spring wheat cultivars Urubo or Sossego were used as resistant checks, and Atlax was used as the susceptible check. For the winter wheat experiments, cultivars Jagalene and Everest were used as the resistant and susceptible checks, respectively (Cruz et al. 2012).

Spreader rows were planted surrounding all experimental plots to generate enough inoculum for wheat blast development throughout the season, in order to not rely solely on natural infection. The spreader rows were inoculated with $M$. oryzae triticum isolate 008 at a concentration of 20,000 spores $\mathrm{ml}^{-1}$ at Feekes GS 3 (late tillering stage) using a $\mathrm{CO}_{2}$-pressurized backpack sprayer. Inoculated rows were covered with plastic tarpaulins for approximately $24 \mathrm{~h}$. The period that inoculated spreader rows were covered was generally lower under field conditions when compared with controlled environments due to the higher day temperatures to avoid heat damage to the plants. At approximately Feekes GS 11.1 (milky ripe stage of grain development) and Feekes GS 11.2 (soft dough stage of grain development), WHB incidence was measured as the average percentage of diseased spikes, and disease severity was measured as the average percentage of infected spikelets in each 1-m-row plot (Cruz et al. 2012). Because we measured disease incidence and severity multiple times, stage of grain development was also measured at each evaluation to ensure the optimal timing for wheat blast evaluation (i.e., soft dough stage of grain development).

Experiments at the adult plant stage. Growth chamber experiments were conducted at the Biosecurity Research Institute (BRI) in Manhattan, KS, U.S.A. Greenhouse experiments (19 total) were conducted at three different locations: the ARS Foreign DiseaseWeed Science Research Unit (FDWSRU) in Fort Detrick MD, U.S.A.; the ANAPO Research Facility in Santa Cruz de la Sierra, Bolivia; and Biotrigo Genética's Research Facility in Passo Fundo, Brazil (Table 3). Approximately five spring wheat seeds were sown into $15-\mathrm{cm}$-diameter pots containing a commercial potting medium (Metro-Mix 360; Hummert International, Earth City, MO, U.S.A.). For the winter wheat entries, a vernalization period of 8 weeks in a cold room $\left(4^{\circ} \mathrm{C}, 9 \mathrm{~h}\right.$ of light, and $15 \mathrm{~h}$ of darkness) was required prior to transplanting the seedlings into the pots. At planting, $3.5 \mathrm{~g}$ of the fertilizer Osmocote (14-14-14) and $1 \mathrm{~g}$ of the insecticide imidacloprid \{1-[(6-chloro-3-pyridinyl)methyl]-N-nitro-2-imidazolidinimine $\}$ were

Table 2. Summary of experiments conducted under field conditions in Bolivia

\begin{tabular}{llrrl}
\hline $\begin{array}{l}\text { Experiment } \\
\text { number }\end{array}$ & Genotypes tested $^{\mathbf{y}}$ & $\boldsymbol{N}^{\mathbf{z}}$ & Year & Location \\
\hline 1 & CIMMYT & 22 & 2017 & Okinawa \\
2 & Biotrigo & 65 & 2017 & Okinawa \\
3 & NAM and EMMER & 65 & 2017 & Okinawa \\
4 & CIMMYT & 20 & 2017 & 26 de Agosto \\
5 & Biotrigo & 61 & 2017 & 26 de Agosto \\
6 & Biotrigo & 192 & 2017 & Quirusillas \\
7 & CIMMYT & 24 & 2018 & Okinawa \\
8 & Biotrigo & 137 & 2018 & Okinawa \\
9 & CIMMYT & 25 & 2018 & Quirusillas \\
10 & Winter wheat & 8 & 2018 & Quirusillas \\
11 & Biotrigo & 72 & 2018 & Quirusillas \\
12 & Biotrigo & 69 & 2018 & Quirusillas \\
\hline
\end{tabular}

y CIMMYT = International Maize and Wheat Improvement Center and $\mathrm{NAM}=$ Nested Association Mapping.

${ }^{\mathrm{z}}$ Number of lines plus susceptible and resistant checks evaluated. 
applied to each pot. Additional insect control occurred as necessary using commercially available insecticides.

For the experiments conducted at the BRI, plants were initially maintained in a greenhouse until the booting stage (Feekes GS 10) (Large 1954), then transferred to the BRI and placed in growth chambers (model PGR15; Conviron, Winnipeg, MB Canada) at day temperatures of $23 \pm 2^{\circ} \mathrm{C}$ and night temperatures of $18 \pm 2^{\circ} \mathrm{C}$. Similarly, heading plants at the ARS-FDWSRU were transferred to the Biosaftey Level-3 Plant Disease Containment Facility greenhouses, with temperatures maintained at $25 \pm 4^{\circ} \mathrm{C}$. The pots were arranged in an incomplete randomized block design with one to four replications, depending on seed availability and growth chamber space. Wheat heads were inoculated approximately 2 days after full head emergence and ratings were taken as previously described. After disease rating was completed, the plants were autoclaved and discarded following biosafety level-3 requirements. Experiments conducted under greenhouse conditions in both the United States and South America followed the same inoculum production, inoculation procedure, and disease rating protocols described above.

Experiments at the seedling stage. To complement WHB evaluations, a few selected non- $2 \mathrm{~N}^{\mathrm{V}} \mathrm{S}$ wheat accessions classified as resistant and moderately resistant were also evaluated at the seedling stage (three-leaf stage) under greenhouse conditions at ANAPO's Research Facility. Seedlings were grown in soil in six-cell starter trays (model TRTD1404; 9GreenBox). Twelve seeds were sown in each tray, representing a replication. Trays were displayed in a randomized complete block design with three replications. Susceptible and resistant checks were included in all experiments. At the three-leaf stage, $6 \mathrm{ml}$ of spore suspension at a concentration of 20,000 spores $\mathrm{ml}^{-1}$ was sprayed on each tray. Immediately after inoculation, the trays were covered with black plastic bags, moistened with water, for $48 \mathrm{~h}$. At 5 and 7 days after inoculation, the second leaf was rated for the percentage of leaf affected by wheat blast (Cruz et al. 2012). Wheat blast severity at the seedling stage was compared with disease severity at the heading stage to better characterize non- $2 \mathrm{~N}^{\mathrm{V}} \mathrm{S}$ resistance and to determine any correlation between resistance and susceptibility at these stages.

Selection of non-2 $\mathbf{N}^{\mathbf{v}} \mathbf{S}$ materials. Five different categories were used to group the wheat genotypes according to their level of disease severity: resistant $(<5 \%)$, moderately resistant $(>5 \%$ and $<25 \%)$, intermediate ( $>25 \%$ and $\leq 45 \%$ ), moderately susceptible $(>45 \%$ and $<65 \%$ ), and susceptible ( $>65 \%)$. Not all materials were evaluated at all location-years. The genotypes grouped as susceptible in the first year of this study were not evaluated again in the following season. Meanwhile, the non- $2 \mathrm{~N}^{\mathrm{V}} \mathrm{S}$ materials showing good levels of resistance (i.e., resistant to intermediate category) were evaluated in more than one experiment.

DNA extraction and molecular marker detection. The wheat genotypes were screened for the presence of the $2 \mathrm{AS} / 2 \mathrm{~N}^{\mathrm{V}} \mathrm{S}$ translocation with the objective of identifying promising alternatives to the known $2 \mathrm{~N}^{\mathrm{V}} \mathrm{S}$-based resistance (Cruz et al. 2016). Genomic DNA was extracted from $100 \mathrm{mg}$ of leaf tissue of 10-day-old seedlings using the Qiagen DNeasy 96 Plant Kit (Qiagen, Hilden, Germany). The quality and quantity of DNA were assessed using a NanoDrop spectrophotometer (NanoDrop Technologies). PCR was performed using the cleaved amplified polymorphic sequences (CAPS) marker protocol modified from a protocol previously described by Helguera et al. (2003). This protocol detects both the $\mathrm{N}$ genome allele and the A genome allele and differentiates homozygous and heterozygous 2AS/ $2 \mathrm{~N}^{\mathrm{V}} \mathrm{S}$ fragments of DNA. Specifically, PCR consisted of $10 \mu \mathrm{l}$ of GoTaq Green Mix (Promega Corporation, Madison, WI, U.S.A.), $200 \mathrm{ng}$ of genomic DNA, and $10 \mu \mathrm{M}$ each $2 \mathrm{~N}^{\mathrm{V}} \mathrm{S}$-specific primers URIC (GGT CGC CCT GGC TTG CAC CT) and ventriup-LN2 (TGC AGC TAC AGC AGT ATG TAC ACA AAA), adjusted to $20 \mu \mathrm{l}$ of total reaction volume. PCR amplification was performed in an Eppendorf thermocycler using the cycling conditions initial denaturing at $94^{\circ} \mathrm{C}$ for $45 \mathrm{~s}$; denaturation at $94^{\circ} \mathrm{C}$ for $45 \mathrm{~s}$, annealing at $64^{\circ} \mathrm{C}$ for $30 \mathrm{~s}$, and extension at $72^{\circ} \mathrm{C}$ for $60 \mathrm{~s}$, repeated for 38 cycles; and a final extension at $72^{\circ} \mathrm{C}$ for $7 \mathrm{~min}$. Following amplification with CAPS primers, $5 \mu \mathrm{l}$ of the PCR was digested with DpnII (New England Biolabs, Ipswich, MA, U.S.A.) restriction enzyme in a $20-\mu l$ reaction, according to manufacturer's protocol. The reaction was incubated at $37^{\circ} \mathrm{C}$ for $1 \mathrm{~h}$. Samples were separated by electrophoresis in $2 \%$ agarose gels and the presence of the 285 -bp N-allele fragment or the 275-bp A-allele fragment was visualized using the SYBR Safe Stain (Invitrogen, Carlsbad, CA, U.S.A.) and a LI-COR detection system (LI-COR Biosciences, Lincoln, NE, U.S.A.). The presence or absence of the $2 \mathrm{~N}^{\mathrm{V}} \mathrm{S}$ segment was also predicted for a subset of these genotypes based on the relative count of wheat and unique $2 \mathrm{~N}^{\mathrm{V}} \mathrm{S}$ alien sequencing tags developed by Gao et al. (2018).

Statistical analyses. Data were analyzed using SAS (version 9.2; SAS Institute, Cary, NC, U.S.A.). For analysis of data from field experiments, disease severity was transformed to logits to linearize the data, although the means and standard errors reported in the results are from the detransformed data. Because disease severity was measured several times at different wheat growth stages, we analyzed it with PROC MIXED using the REPEATED statement for the analysis of repeated measurements. Growth stage was used as a covariate and means of the wheat genotypes of interest were compared with the mean of the susceptible checks measured at soft dough stage of grain

Table 3. Summary of experiments conducted under growth chamber and greenhouse conditions

\begin{tabular}{|c|c|c|c|c|c|}
\hline Experiment & Genotypes evaluated $^{x}$ & $N^{\mathbf{y}}$ & Isolate & Environment $^{\mathrm{z}}$ & Location \\
\hline 1 & Diverse set; spring wheat & 9 & B-71 & BRI & United States \\
\hline 2 & Diverse set; spring wheat & 14 & B-71 & BRI & United States \\
\hline 3 & Winter wheat & 4 & B-71 & BRI & United States \\
\hline 4 & NAM & 34 & B-71 & BRI & United States \\
\hline 5 & Aegilops tauschii & 16 & B-71 & BRI & United States \\
\hline 6 & A. tauschii & 38 & B-71 & ARS-FDWSRU & United States \\
\hline 7 & Diverse set; spring wheat & 19 & 008 & ANAPO & Bolivia \\
\hline 8 & Winter wheat & 23 & 008 & ANAPO & Bolivia \\
\hline 9 & EMMER & 55 & 008 & ANAPO & Bolivia \\
\hline 10 & NAM and EMMER & 56 & 008 & ANAPO & Bolivia \\
\hline 11 & CIMMYT & 9 & 008 & ANAPO & Bolivia \\
\hline 12 & Biotrigo & 27 & 16МoT001 & Biotrigo & Brazil \\
\hline 13 & CIMMYT & 60 & B-71 & ARS-FDWSRU & United States \\
\hline 14 & A. tauschii & 32 & B-71 & BRI & United States \\
\hline 15 & A. tauschii & 25 & B-71 & BRI & United States \\
\hline 16 & Winter wheat & 8 & B-71 & BRI & United States \\
\hline 17 & Biparental population & 188 & 008 & ANAPO & Bolivia \\
\hline
\end{tabular}

${ }^{x}$ NAM $=$ Nested Association Mapping and CIMMYT = International Maize and Wheat Improvement Center.

${ }^{y}$ Number of genotypes evaluated plus susceptible and resistant checks.

${ }^{\mathrm{z}}$ BRI = Biosecurity Research Institute, ARS-FDWSRU = Agricultural Research Service Foreign Disease-Weed Science Research Unit, and ANAPO = Association of Producers of Oilseeds and Wheat. 
development (i.e., the optimal time for wheat blast evaluation). The presence of the $2 \mathrm{~N}^{\mathrm{V}} \mathrm{S}$ translocation and genotype within $2 \mathrm{~N}^{\mathrm{V}} \mathrm{S}$ were treated as fixed effects. Environment (combination of year and location), experiment within environment, and block within experiment were treated as random effects. For the experiments under controlled-environment conditions, we analyzed the disease severity evaluated at 14 days (i.e., susceptible check averaged $90 \%$ or more of disease severity) after inoculation using PROC MIXED. In the analysis of field data, the presence of the $2 \mathrm{~N}^{\mathrm{V}} \mathrm{S}$ translocation and genotypes within $2 \mathrm{~N}^{\mathrm{V}} \mathrm{S}$ were treated as fixed effects. Experiment within environment (e.g., BRI, ANAPO, Biotrigo, or ARS-FDWSRU) and experiment within genotype and $2 \mathrm{~N}^{\mathrm{V}} \mathrm{S}$ were treated as random effects.

\section{Results}

Field experiments. Mean wheat blast severity across all entries combined was not significantly different among location-years $(P=$ $0.11)$ and among experiments within the same location-year $(P=$ 0.07) (Supplementary Table S1). However, there was a significant difference between incidence and severity of the susceptible versus resistant checks at soft dough stage of grain development among the 12 individual experiments $(P<0.001)$ (Supplementary Table $\mathrm{S} 2$ ). Disease incidence of the susceptible checks was $>50 \%$ and disease severity averaged $25 \%$ or more in 9 of 12 experiments. The lowest disease incidence $(1.2 \%)$ and severity $(0.7 \%)$ occurred in a field in Quirusillas 2017 (experiment 6), where a moderately resistant check was inadvertently sown instead of a susceptible check. Disease incidence of the resistant checks was $<4 \%$ in 11 of 12 experiments and only two experiments averaged disease severity $>2 \%$. Due to the known level of resistance and uniform distribution in the field, disease incidence and severity of the susceptible checks provided an estimation of the overall disease intensity within each experiment and were used to standardize the disease variability across the field. Overall, WHB intensity was low to medium in all location-years of this study. This was due to dry environmental conditions in the region, and the absence of optimal temperatures $\left(25\right.$ to $\left.30^{\circ} \mathrm{C}\right)$ and high relative humidity ( $>90 \%$ ) throughout the wheat growing season. Nevertheless, supplemental irrigation and spreader borders inoculated early in the season made the collected field data a valuable resource.

Of the 526 wheat accessions evaluated under field conditions, 332 were positive and 194 were negative for the presence of the $2 \mathrm{~N}^{\mathrm{V}} \mathrm{S}$ translocation. There was a significant difference between the mean disease severity of the $2 \mathrm{~N}^{\mathrm{V}} \mathrm{S}$ and the non- $2 \mathrm{~N}^{\mathrm{V}} \mathrm{S}$ groups $(P<$ 0.001 ). Within the $2 \mathrm{~N}^{\mathrm{V}} \mathrm{S}$ accessions, head blast severity ranged from 0 to $87 \%$, with mean severity of $2 \%$. Within the non- $2 \mathrm{~N}^{\mathrm{V}} \mathrm{S}$ entries, disease severity ranged from 0 to $99 \%$, with mean of $16 \%$. Although this difference was statistically significant, the distribution of both groups was skewed toward resistance, probably due to the low disease pressure under field conditions and the unbalanced number of $2 \mathrm{~N}^{\mathrm{V}} \mathrm{S}$ and non-2N $\mathrm{N}^{\mathrm{V}} \mathrm{S}$ entries (Fig. 1A and B). Differences between $2 \mathrm{~N}^{\mathrm{V}} \mathrm{S}$ and non- $2 \mathrm{~N}^{\mathrm{V}} \mathrm{S}$ groups in individual field experiments are shown in Supplementary Figure S1. In all experiments, disease incidence and severity of the $2 \mathrm{~N}^{\mathrm{V}} \mathrm{S}$ materials were significantly lower than that of non- $2 \mathrm{~N}^{\mathrm{V}} \mathrm{S}$ genotypes $(P<0.001)$. Wheat blast intensity can vary considerably from year to year even in the hotspot areas. Given the disease intensity in the field experiments, there was a $90 \%$ cumulative probability that $2 \mathrm{~N}^{\mathrm{V}} \mathrm{S}$ wheat genotypes scored $5 \%$ or less (i.e., resistant category) severity, while the probability was lower $(50 \%)$ for the non- $2 \mathrm{~N}^{\mathrm{V}} \mathrm{S}$ genotypes (Fig. 1C).

Greenhouse experiments. The disease severity under controlled environments (greenhouse and growth chamber) was significantly higher than that in field experiments. Under controlled environments, critical environmental variables (i.e., temperature, relative humidity, and leaf wetness) were controlled and heads were inoculated individually. Similar to field experiments, a significant difference was observed between $2 \mathrm{~N}^{\mathrm{V}} \mathrm{S}$ and non- $2 \mathrm{~N}^{\mathrm{V}} \mathrm{S}$ groups across controlledenvironment experiments. For both groups, disease severity ranged from 0 to $100 \%$ at 14 days after inoculation. Severity distribution of the $2 \mathrm{~N}^{\mathrm{V}} \mathrm{S}$ group was skewed toward resistance, with mean severity of $22 \%$. On the other hand, severity distribution of the non- $2 \mathrm{~N}^{\mathrm{V}} \mathrm{S}$ group was skewed toward susceptibility, with mean severity of $78 \%$ (Fig. 2A and B). Based on the data collected from controlledenvironment experiments, where the disease pressure was higher compared with field experiments, there was a $15 \%$ cumulative probability that a $2 \mathrm{~N}^{\mathrm{V}} \mathrm{S}$ genotype was in the resistant category. This probability was null for the non- $2 \mathrm{~N}^{\mathrm{V}} \mathrm{S}$ genotypes. Considering disease severity at $25 \%$, which is the upper limit for moderately resistant genotypes, there was a $65 \%$ cumulative probability that a $2 \mathrm{~N}^{\mathrm{V}} \mathrm{S}$ genotype scored $25 \%$ or less, and only $5 \%$ probability for non- $2 \mathrm{~N}^{\mathrm{V}} \mathrm{S}$ genotypes (Fig. 2C).

Three different isolates were used under controlled environmental conditions in the different experimental sites and countries. Despite the presence of wheat blast, Brazil and Bolivia do not allow the
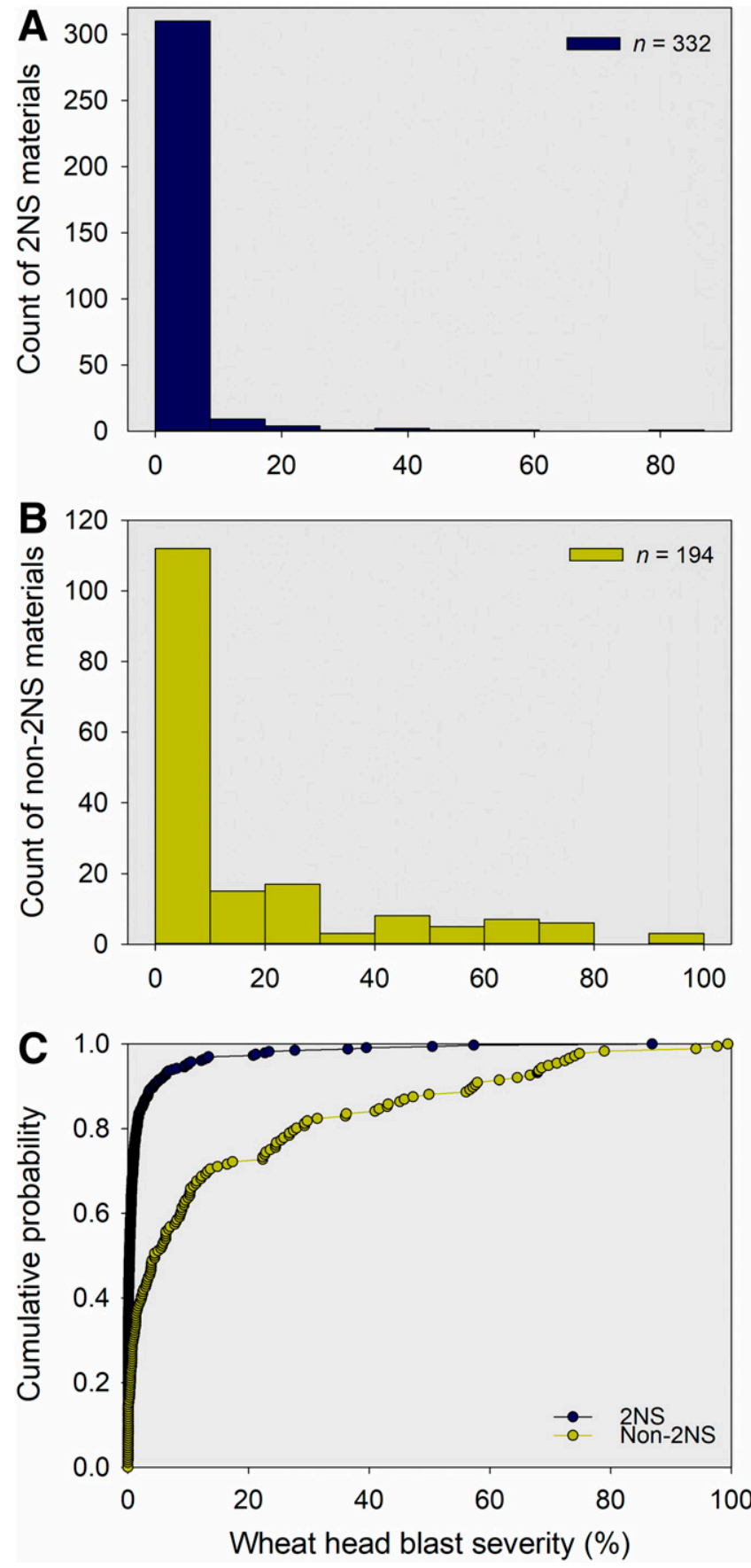

Fig. 1. Data combined from 12 field experiments. Blast disease severity frequency distribution evaluated at soft dough stage of grain development for $A, 2 N^{V} S$ and $B$, non-2NVS genotypes. C, Cumulative probability of head blast severity for $2 N^{V} S$ (dark dots) and non-2N $\mathrm{V}^{\mathrm{S}}$ genotypes (light dots). 
entrance of foreign wheat isolates to avoid the introduction of new and possibly more aggressive races. Resistance of $2 \mathrm{~N}^{\mathrm{V}} \mathrm{S}$ and non$2 \mathrm{~N}^{\mathrm{V}} \mathrm{S}$ groups and within each group was statistically different for the three isolates. In both groups, the Brazilian isolate, 16MoT001, was the most aggressive $\left(2 \mathrm{~N}^{\mathrm{V}} \mathrm{S}=82.1 \%\right.$ and non- $2 \mathrm{~N}^{\mathrm{V}} \mathrm{S}=97.2 \%$ mean severity). The non- $2 \mathrm{~N}^{\mathrm{V}} \mathrm{S}$ group showed similar averaged severity for the two Bolivian isolates $(\mathrm{B}-71=71 \%$ and $008=68 \%$ ). There was a greater difference within the $2 \mathrm{~N}^{\mathrm{V}} \mathrm{S}$ group, with a mean severity of $29.2 \%$ for B-71 and of $18.8 \%$ for the 008 isolate (Fig. 3). Initially, when tested against the set of differentials, the three isolates were classified as race 2 . However, these additional experiments have shown a substantially higher level of aggressiveness associated with Brazilian isolate 16MoT001, especially when tested against
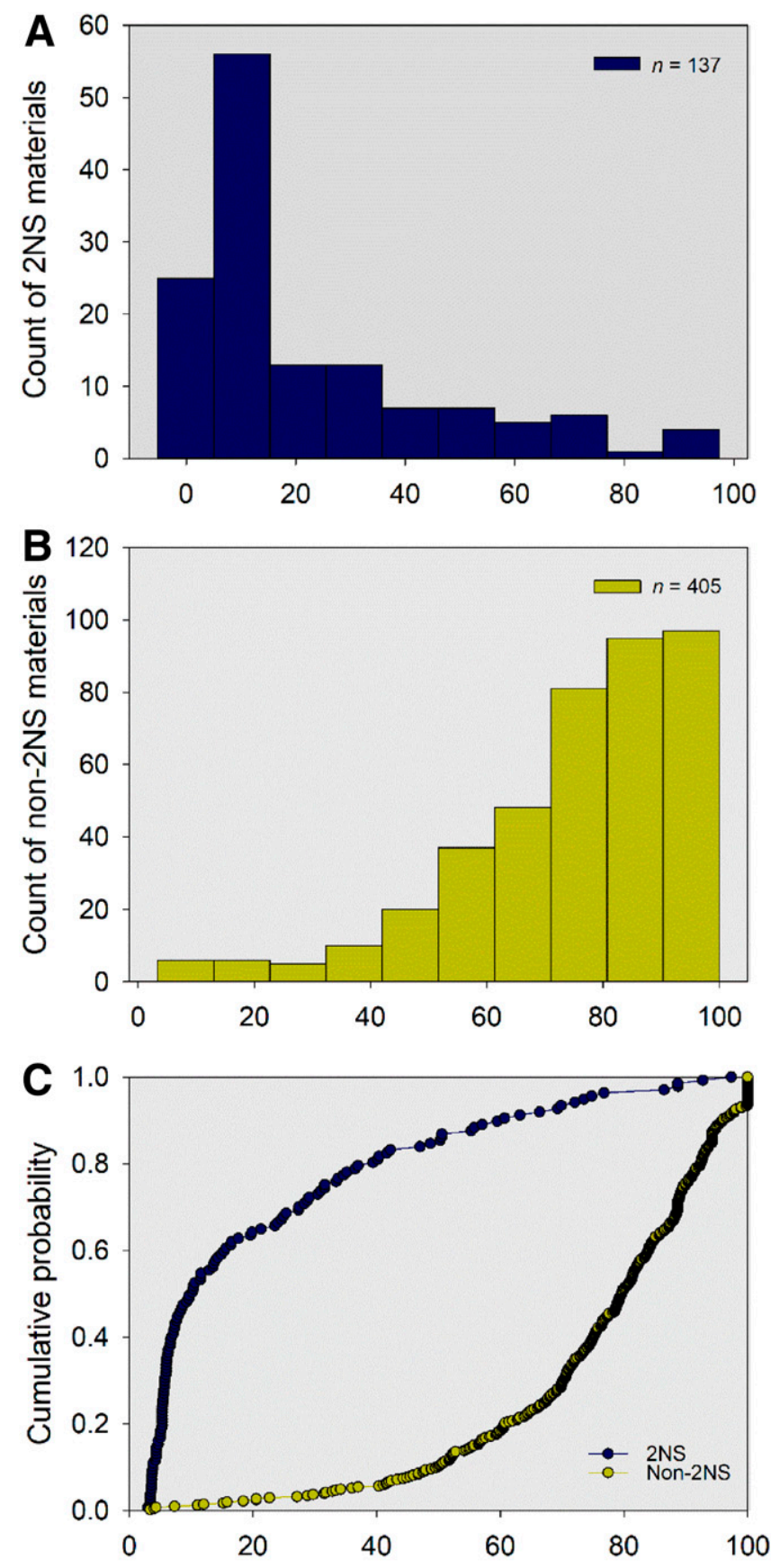

Wheat head blast severity (\%)

Fig. 2. Data combined from 17 experiments under controlled-environment conditions. Blast disease severity frequency distribution evaluated at 14 days after inoculation for A, $2 N^{V} S$ and $B$, non-2N $N^{V} S$ genotypes. C, Cumulative probability of head blast severity for $2 \mathrm{~N}^{\mathrm{V}} \mathrm{S}$ (dark dots) and non-2N $\mathrm{N}^{\mathrm{S}} \mathrm{S}$ genotypes (light dots). moderately resistant $2 \mathrm{~N}^{\mathrm{V}} \mathrm{S}$ genotypes. Additional experiments are needed to determine whether newer Brazilian isolates are becoming more aggressive and breaking the $2 \mathrm{~N}^{\mathrm{V}} \mathrm{S}$ resistance.

Selection of non- $2 \mathrm{~N}^{\mathrm{V}} \mathrm{S}$ materials. A few non- $2 \mathrm{~N}^{\mathrm{V}} \mathrm{S}$ genotypes displayed satisfactory levels of wheat blast resistance. Among the spring wheat materials, four non- $2 \mathrm{~N}^{\mathrm{V}} \mathrm{S}$ CIMMYT lines (i.e., $\mathrm{CM}$ 22, CM 49, CM 52, and CM 61) exhibited consistent intermediate to high levels of resistance under both field and controlledenvironment conditions. The first experiment was conducted at ARS-FDWSRU with 93 CIMMYT lines (Supplementary Table S3). The best non- $2 \mathrm{~N}^{\mathrm{V}} \mathrm{S}$ lines were selected and evaluated under field conditions in Bolivia for a total of four location-years (Fig. 4). In the winter wheat season of 2017 , five non- $2 \mathrm{~N}^{\mathrm{V}} \mathrm{S}$ CIMMYT lines plus checks were evaluated in two locations, Okinawa and 26 de Agosto. At both locations, the rank of the materials evaluated was the same. The lines CM 36, CM 52, and CM 22 and the resistant $2 \mathrm{~N}^{\mathrm{V}} \mathrm{S}$ checks Urubo and AN120 averaged less than $13 \%$ disease incidence and less than $5 \%$ disease severity. The susceptible check Atlax averaged $50 \%$ or more disease incidence and at least $25 \%$ disease severity. Line CM 43 had the highest incidence (65\%) and severity (55\%) in both experiments. In 2018, one experiment was conducted in the summer season in Quirusillas and one experiment in the winter season in Okinawa. In addition to the lines tested in 2017, lines CM 27, CM 36, and CM 49 and one moderately resistant check (Sossego) were added. In contrast to the previous year, genotypes performed differently in the two locations, which can be partially explained by the different seasons (summer versus winter seasons). At both locations, the three resistant checks ranked as the most resistant, but not in the same order. In Quirusillas, the susceptible check averaged 99\% of incidence and $87.5 \%$ of severity and in Okinawa, averages were $78.3 \%$ and $58.8 \%$. Only one of the three additional lines tested in 2018 performed well. The line CM 27 was grouped as resistant in Quirusillas with average severity of $4.4 \%$, and as intermediate in Okinawa, with severity average of $37.5 \%$. CM 49 was grouped as moderately susceptible and CM 36 as susceptible in both experiments, whereas CM 52 was grouped as intermediate. Lines CM 61 and CM 22 were grouped as intermediate and as moderately susceptible, respectively, in Quirusillas. The opposite reaction was observed in Okinawa for these two lines.

Under greenhouse conditions, lines CM 22, CM 49, CM 52, and CM 61 averaged less than $41 \%$ at 14 days after inoculation (Fig. 5). The two non- $2 \mathrm{~N}^{\mathrm{V}} \mathrm{S}$ susceptible checks, Atlax and Bob White, averaged 77.3 and $95.75 \%$, respectively. The moderately resistant (Sossego) and the resistant (Urubo) $2 \mathrm{~N}^{\mathrm{V}} \mathrm{S}$ checks averaged 8.5 and $1.2 \%$, respectively (Fig. 5). To better characterize the non- $2 \mathrm{~N}^{\mathrm{V}} \mathrm{S}$ resistance in these four CIMMYT lines, seedling resistance was also evaluated in a controlled environment (Fig. 6). Seedling blast severity of

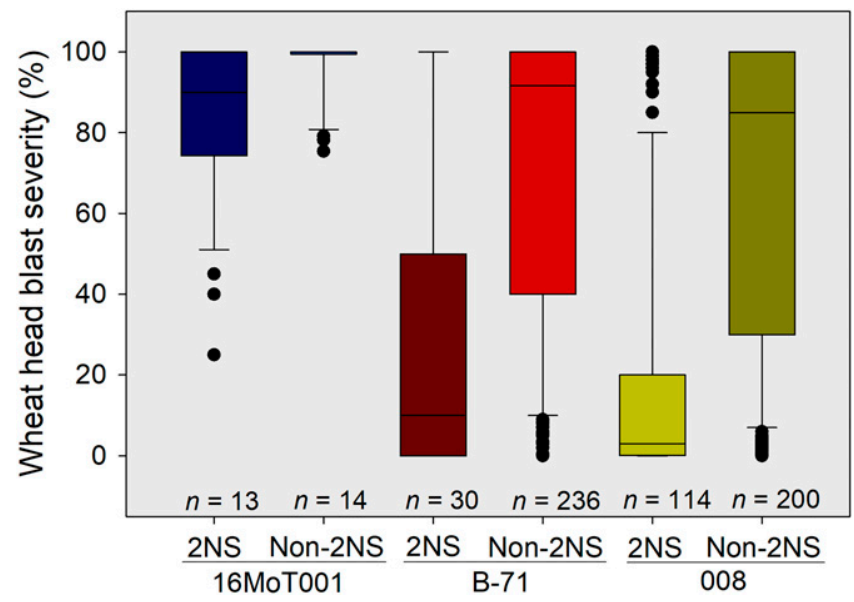

Fig. 3. Disease severity to wheat blast for $2 N^{V} S$ and non-2N ${ }^{V} S$ genotypes tested against three Magnaporthe oryzae triticum isolates (Brazilian isolate 16MoT001, Bolivian isolate B-71, and Bolivian isolate 008) used for controlled-environment experiments. 
the four lines was lower than both susceptible and resistant checks (Fig. 6). There was a weak but significant positive linear relationship $(P<0.05)$ between seedling and head resistance $\left(r^{2}=0.48\right)$. At the seedling stage, resistant check Urubo and lines CM 52, CM 49, CM 22, and CM 61 were considered resistant; Atlax, Sossego, and CM 36 were moderately resistant; and CM 43 and Bob White were intermediate. The seedling results are data combined from two independent experiments $\left(r^{2}=0.78\right)$. At the head stage under controlled experiments, Urubo was placed into the resistant group; Sossego and CM 49 were moderately resistant; CM 52, CM 22, and CM 61 were intermediate; and CM 36, CM 43, and both susceptible checks (Atlax and Bob White) were placed in the susceptible group $(>65 \%)$. Only the resistant checks Urubo and Sossego were placed in the same category at both seedling and head experiments. Surprisingly, both susceptible checks (Atlax and Bob White) did not show high levels of disease severity at the seedling stage. However, Bob White had the greatest disease severity in both experiments.

In addition to the spring wheat lines, one $A$. tauschii line (TA10142) averaged $2.5 \%$ severity under controlled experiments (Fig. 7). Another three lines-TA1624 (16\%), TA 1667 (21.6\%), and TA10140 $(25.7 \%)$-were placed into the moderately resistant category. From the remaining TA lines screened, 6 lines were classified as intermediate, 9 lines as moderately susceptible, and 49 lines as susceptible. The susceptible check averaged $100 \%$ at 14 days after inoculation (Supplementary Table S4). These lines were not evaluated under field conditions due to the challenge of planting winter wheat in South America. Selected TA lines will serve as parents in biparental and backcrossing populations with a spring background, enabling their further evaluation under field conditions in South America.

\section{Discussion}

Screening of more than 780 accessions of elite spring and winter wheat cultivars, modern breeding lines, landraces, and wheat wild relatives resulted in the identification of only 8 non- $2 \mathrm{~N}^{\mathrm{V}} \mathrm{S}$ accessions

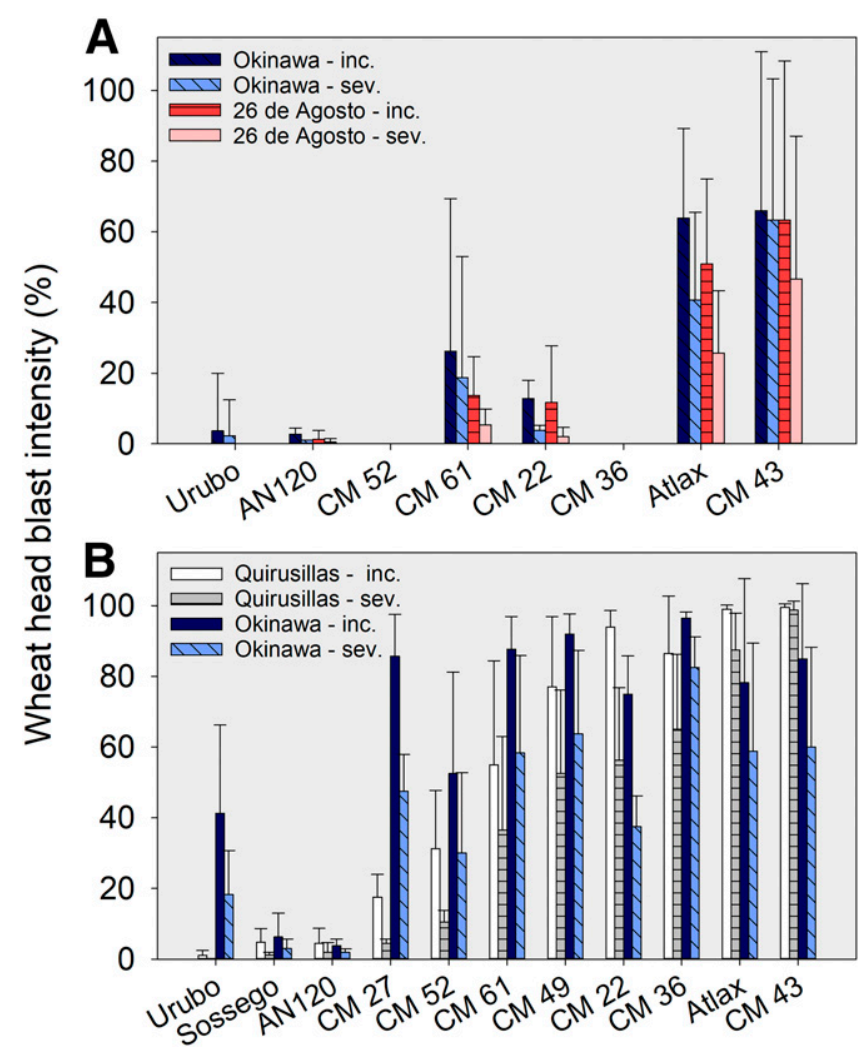

Fig. 4. Wheat head blast disease incidence (inc.) and severity (sev.) of CIMMYT breeding lines, plus checks under field conditions in two locations during A, 2017 and B, 2018. Atlax was the non-2N ${ }^{V_{S}}$ susceptible check and Urubo, Sossego, and AN120 were the $2 \mathrm{~N}^{\mathrm{V}} \mathrm{S}$ resistant checks. Disease intensity was measured at soft dough stage of grain development. with moderate levels of resistance to WHB. This is equivalent to only $1 \%$ of the evaluated genotypes offering some level of resistance, highlighting the rare occurrence of inherent protection to this devastating disease. Within the selected materials, four accessions were derived from the CIMMYT breeding program (CM 22, CM 49, CM 52, and CM 61). The resistance in these lines was also characterized at the seedling stage and showed weak correlation with head infection. The largest yield losses are associated with head infection. Our results agree with those of Cruz et al. (2012) and Maciel et al. (2014) that seedling evaluations cannot be used as a surrogate for resistance at the heading stage.

The remaining four promising non- $2 \mathrm{~N}^{\mathrm{V}} \mathrm{S}$ accessions evaluated were A. tauschii accessions (TA 10142, TA1624, TA1667, and TA10140), one of the three progenitors of bread wheat. Wild relatives of wheat are a valuable source of genetic diversity and have played an important role in wheat improvement worldwide over the last century (Autrique et al. 1995; Friebe et al. 1996; Hajjar and Hodgkin 2007; Warburton et al. 2006). One of the drawbacks of the introgression of genes from wild relatives is the linkage drag (i.e., the addition of undesirable or deleterious genes that negatively affect grain yield and quality) (Zhang et al. 2017). Fortunately, much effort has been made to minimize linkage drag and to increase the use of alien genes in breeding programs (Molnár et al. 2016; Zhang et al.

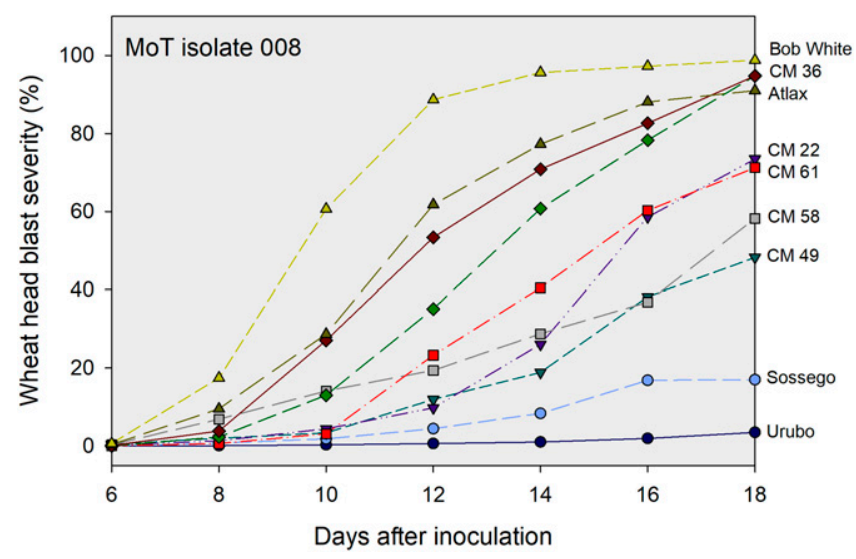

Fig. 5. Wheat head blast disease severity of non-2NV $\mathrm{V}_{S}$ CIMMYT lines plus checks under controlled environmental conditions in Bolivia using Magnaporthe oryzae triticum isolate 008 . Urubo and Sossego were the $2 \mathrm{~N}^{\mathrm{V}} \mathrm{S}$ resistant checks, and Atlax and Bob White were the susceptible non-2NV $\mathrm{V}_{S}$ checks. The optimal timing for disease assessment in this experiment was 14 days after inoculation.

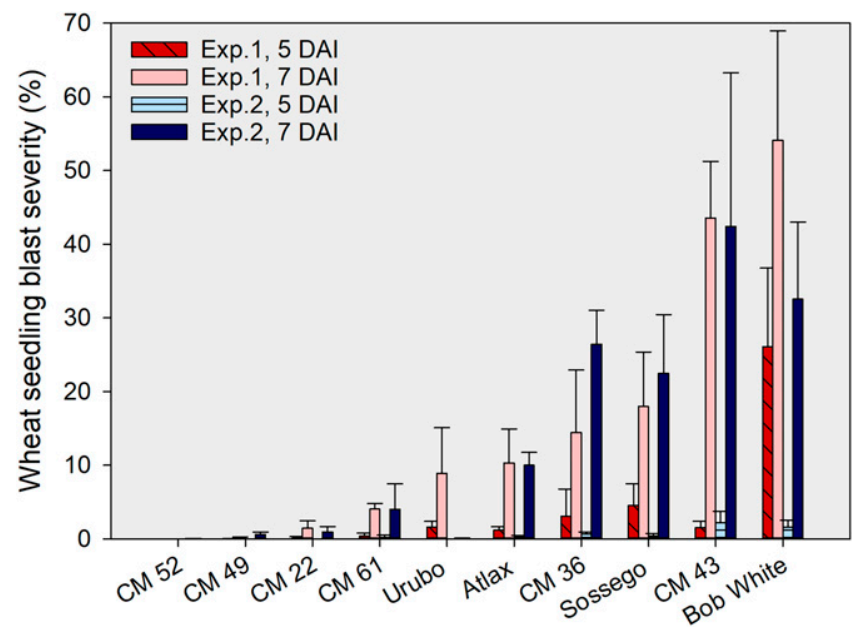

Fig. 6. Wheat blast disease severity at seedling stage of CIMMYT lines plus checks. Experiments were repeated twice (Exp. 1 and Exp. 2) under controlled-environment conditions in Bolivia using Magnaporthe oryzae triticum isolate 008. DAI = days after inoculation. Atlax and Bob White were the non-2N $\mathrm{V}_{S}$ susceptible checks and Urubo and Sossego the $2 \mathrm{~N}^{\mathrm{V}} \mathrm{S}$ resistant checks. 
2017). Nonetheless, introgression of resistance from these accessions into commercial wheat lines is still laborious and time consuming.

Though a large and highly diverse set of accessions was screened in this study, the frequency of resistance to wheat blast was extremely low, underscoring the threat that wheat blast poses to wheat production worldwide. In addition, we showed preliminary data suggesting an increase in the aggressiveness of a new Brazilian isolate, 16 MoT001, which could lead to the breakdown of the only effective source of WHB resistance currently available, the $2 \mathrm{~N}^{\mathrm{V}} \mathrm{S}$ translocation. An increase in aggressiveness of $M$. oryzae triticum isolates was already observed when comparing isolates collected in the late 1980 s to isolates collected after 2010, decreasing the level of resistance of some $2 \mathrm{~N}^{\mathrm{V}} \mathrm{S}$-based cultivars under high levels of disease pressure (Anh et al. 2015; Cruz et al. 2012; Cruz and Valent 2017; Cruz et al. 2016). An additional possibility that could help explain the higher levels of disease observed with $16 \mathrm{MoT} 001$ in the $2 \mathrm{~N}^{\mathrm{V}} \mathrm{S}$ cultivars evaluated would be a strong isolate-cultivar interaction, as demonstrated in previous studies (Cruz et al. 2016; Maciel et al. 2014; Urashima et al. 2004). Because only a limited number of $2 \mathrm{~N}^{\mathrm{V}} \mathrm{S}$ accessions were tested against 16MoT001, further experiments are needed to evaluate the reaction of a broader panel of $2 \mathrm{~N}^{\mathrm{V}} \mathrm{S}$ materials with isolates recently collected from wheat-blastaffected regions.

Although not evaluated in this study, five $R$ genes ( $R m g 2, R m g 3$, $R m g 7, R m g 8$, and $R m g G R 119)$ were previously reported as effective against wheat blast (Anh et al. 2015; Tagle et al. 2015; Wang et al. 2018). However, genes $R m g 2, R m g 3$, and $R m g 7$ are no longer effective at the adult plant stage against newer isolates. As a future goal,

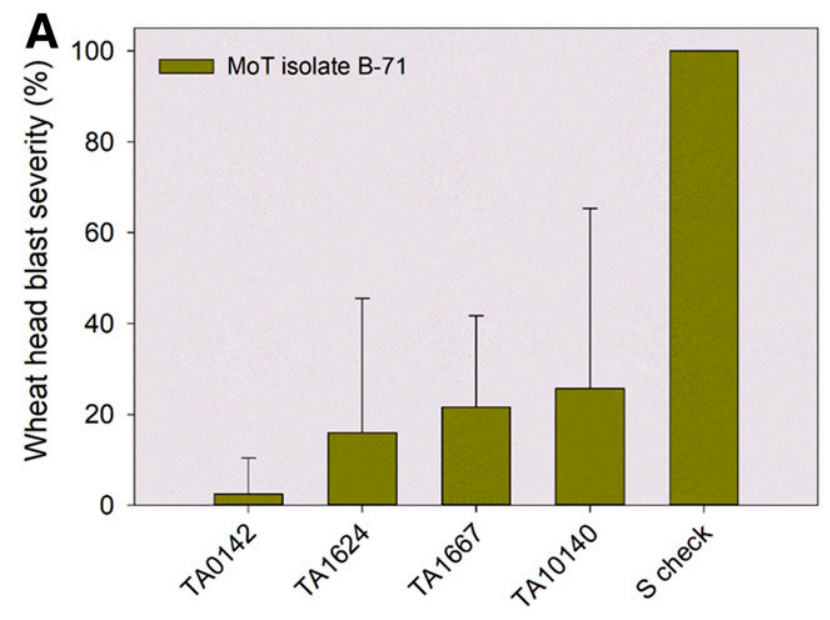

Ae. tauschii
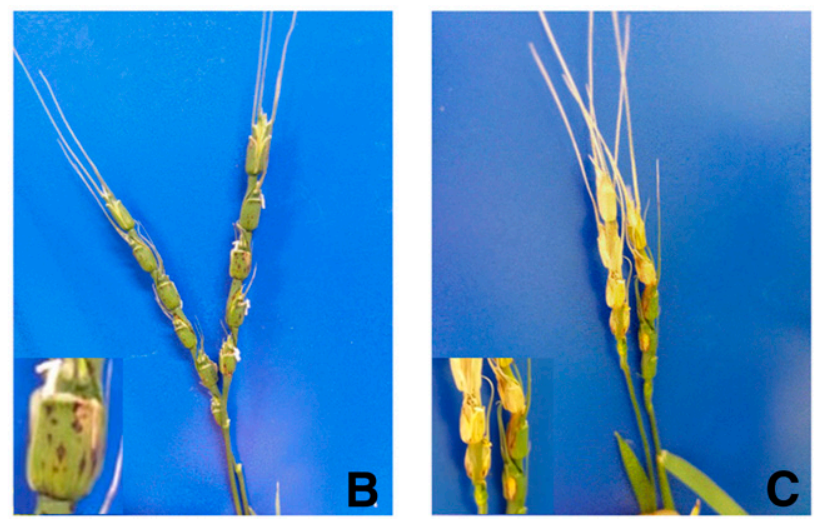

Fig. 7. A, Wheat blast disease severity of four Aegilops tauschii accessions plus the susceptible check Cavalier evaluated at 14 days after inoculation under controlledenvironment conditions using Magnaporthe oryzae triticum isolate B-71. B, Dark flecks (hypersensitive response) indicate a resistant reaction and $\mathbf{C}$, individual large lesions to totally bleached heads indicates a susceptible reaction. we plan to test Rmg8 and RmgGR119 under field conditions in Bolivia and against newer and more aggressive $M$. oryzae triticum isolates under biosafety level-3 laboratories in the United States. If $R m g 8$ and $R m g G R 119$ are indeed effective sources of WHB resistance, it is imperative to include these genes in wheat breeding programs and to introgress them into grown $2 \mathrm{~N}^{\mathrm{V}} \mathrm{S}$ cultivars. Given the emergence of newer and more aggressive $M$. oryzae triticum races and the identification of novel sources of resistance, a broader set of wheat differentials must be established. Based on our findings combined with others (Anh et al. 2015; Cruz et al. 2016; Tagle et al. 2015; Wang et al. 2018), we suggest several genotypes, including $2 \mathrm{~N}^{\mathrm{v}} \mathrm{S}$ - and non- $2 \mathrm{~N}^{\mathrm{v}} \mathrm{S}$-based accessions (including recent findings) with different levels of WHB resistance that potentially could be included in a new set of wheat differentials (Supplementary Table S5). It is important that the different blast research programs adopt the same set of wheat differentials for race designation.

An appropriate disease management strategy would include crop rotation with a nonhost and rotation of active ingredients in both seed treatment and foliar fungicide applications. Cultural practices such as the removal of secondary hosts or infected residue and the adjustment of planting date could also play an important role in wheat blast control. The strategies cited above must be combined with the use of resistant cultivars, which ideally would carry more than one $R$ gene. Critical follow-up to this research is to develop and evaluate several populations from the eight accessions identified in this study to characterize the genetics of resistance in these lines and develop molecular markers linked to $R$ genes effective to new and highly aggressive races. These resistant accessions can then be incorporated into wheat breeding programs to introgress resistance into cultivated wheat varieties.

\section{Acknowledgments}

We thank Biotrigo Genetica for providing support with the experiments conducted in Brazil; M. G. Rivadeneira from CIAT for the help with inoculum preparation; D. F. Baldelomar, J. Cuellar, and D. Coimbra from ANAPO for their help with field and greenhouse activities; A. Cruz (Kansas State University and Purdue University) and E. Navia and M. Dalby (Kansas State University) for their general support; M. G. Hoffmann and N. Rodrigues from Biotrigo Genetica for their help with inoculation and disease rating in the experiments conducted in Brazil; E. O. Garcia (Kansas State University and Louisiana State University) for his support with PCR protocol; K. Keller, A. Kloos, and J. Lehr of ARS-FDWSRU for the planting, inoculation, and scoring of wheat germplasm at ARS-FDWSRU; and R. Lollato for his useful suggestions.

\section{Literature Cited}

Anh, V. L., Anh, N. T., Tagle, A. G., Vy, T. T. P., Inoue, Y., Takumi, S., Chuma, I., and Tosa, Y. 2015. Rmg8, a new gene for resistance to Triticum isolates of Pyricularia oryzae in hexaploid wheat. Phytopathology 105:1568-1572.

Anh, V. L., Inoue, Y., Asuke, S., Vy, T. T. P., Anh, N. T., Wang, S., Chuma, I., and Tosa, Y. 2018. Rmg8 and Rmg7, wheat genes for resistance to the wheat blast fungus, recognize the same avirulence gene AVR-Rmg8. Mol. Plant Pathol. 19: $1252-1256$

Autrique, E., Singh, R. P., Tanksley, S. D., and Sorrells, M. E. 1995. Molecular markers for four leaf rust resistance genes introgressed into wheat from wild relatives. Genome 38:75-83.

Barea, G., and Toledo, J. 1996. Identificacion y zonificación de Pyricularia (Pyricularia oryzae) en el cultivo de trigo en el departamento de Santa Cruz. Pages 76-86 in: Centro de Investigación Agrícola Tropical. Informe Técnico, Proyecto de Investigación Trigo, Santa Cruz de la Sierra, Bolivia.

Bariana, H. S., and McIntosh, R. A. 1993. Cytogenetic studies in wheat. XV Location of rust resistance genes in VPM1 and their genetic linkage with other disease resistance genes in chromosome 2A. Genome 36:476-482.

Cardoso, C. A. de A., Reis, E. M., and Moreira, E. N. 2008. Development of a warning system for wheat blast caused by Pyricularia grisea. Summa Phytopathol. 34:216-221.

Coelho, M. A. D. O., Torres, G. A. M., Cecon, P. R., and Santana, F. M. 2016 Sowing date reduces the incidence of wheat blast disease. Pesqui. Agropecu. Bras. 51:631-637.

Couch, B. C., and Kohn, L. M. 2002. A multilocus gene genealogy concordant with host preference indicates segregation of a new species, Magnaporthe oryzae, from M. grisea. Mycologia 94:683-693.

Cruz, C. D., Bockus, W. W., Stack, J. P., Tang, X., Valent, B., Pedley, K. F., and Peterson, G. L. 2012. Preliminary assessment of resistance among U.S. wheat cultivars to the Triticum pathotype of Magnaporthe oryzae. Plant Dis. 96: 1501-1505.

Cruz, C. D., Kiyuna, J., Bockus, W. W., Todd, T. C., Stack, J. P., and Valent, B. 2015. Magnaporthe oryzae conidia on basal wheat leaves as a potential source of wheat blast inoculum. Plant Pathol. 64:1491-1498. 
Cruz, C. D., Peterson, G. L., Bockus, W. W., Kankanala, P., Dubcovsky, J., Jordan, K. W., Akhunov, E., Chumley, F., Baldelomar, F. D., and Valent, B. 2016. The 2NS translocation from Aegilops ventricosa confers resistance to the Triticum pathotype of Magnaporthe oryzae. Crop Sci. 56:990-1000.

Cruz, C. D., Santana, F. M., Todd, T. C., Maciel, J. L. N., Kiyuna, J., Baldelomar, D. F., Cruz, A. P., Lau, D., Seixas, C. S., Goulart, A. C., Sussel, A. A., Schipanski, C. A., Chagas, D. F., Coelho, M., Montecelli, T. D. N., Utiamada, C., Custodio, A. P., Rivanadeira, M. G., Bockus, W. W., and Valent, B. 2018. Multi-environment assessment of fungicide performance for managing wheat head blast (WHB) in Brazil and Bolivia. Trop. Plant Pathol. 44:183-191.

Cruz, C. D., and Valent, B. 2017. Wheat blast disease: Danger on the move. Trop. Plant Pathol. 42:210-222.

Friebe, B., Jiang, J., Raupp, W. J., McIntosh, R. A., and Gill, B. S. 1996. Characterization of wheat-alien translocations conferring resistance to diseases and pests: Current status. Euphytica 91:59-87.

Gao, L., Dorn, K., Rife, T. W., Wang, X., Lemes, C., Clinesmith, M., Silva, P., Fritz, A., Stein, N., Mascher, M., and Poland, J. 2018. Completion of the 'Jagger' wheat genome leads to identification of Aegilops ventricosa $2 \mathrm{NS}$ translocation and its impact in wheat breeding. In: Plant Anim. Genome Conf. XXVI.

Gladieux, P., Condon, B., Ravel, S., Soanes, D., Maciel, J. L. N., Nhani, A., Chen, L., Terauchi, R., Lebrun, M. H., Tharreau, D., Mitchell, T., Pedley, K. F., Valent, B., Talbot, N. J., Farman, M., and Fournier, E. 2018. Gene flow between divergent cereal-and grass-specific lineages of the rice blast fungus Magnaporthe oryzae. MBio 9:e1219-17.

Goulart, A. C. P., Sousa, P. G., and Urashima, A. S. 2007. Danos em trigo causados pela infecção de Pyricularia grisea. Summa Phytopathol. 33:358-363.

Hajjar, R., and Hodgkin, T. 2007. The use of wild relatives in crop improvement: A survey of developments over the last 20 years. Euphytica 156:1-13.

Helguera, M., Khan, I. A., Kolmer, J., Lijavetzky, D., Zhong-qi, L., and Dubcovsky, J. 2003. PCR assays for the Lr37-Yr17-Sr38 cluster of rust resistance genes and their use to develop isogenic hard red spring wheat lines. Crop Sci. 43:1839-1874.

Jahier, J. P., Abelard, P., Tanguy, M., Dedryver, F., Rivoal, R., Khatkar, S., Bariana, H. S., and Koebner, R. 2001. The Aegilops ventricosa segment on chromosome 2AS of the wheat cultivar "VPM1" carries the cereal cyst nematode resistance gene Cre5. Plant Breed. 120:125-128.

Kohli, M. M., Mehta, Y. R., Guzman, E., de Viedma, L., and Cubilla, L. E. 2011. Pyricularia blast-A threat to wheat cultivation. Czech J. Genet. Plant Breed. 47:S130-S134.

Large, E. C. 1954. Growth stages in cereals illustration of the Feekes scale. Plant Pathol. 3:128-129.

Maciel, J. L. N., Ceresini, P. C., Zala, M., McDonald, B. A., Castroagudin, V. L., and Kema, G. H. J. 2014. Population structure and pathotype diversity of the wheat blast pathogen Magnaporthe oryzae 25 years after its emergence in Brazil. Phytopathology 104:95-107.

Malaker, P. K., Barma, N. C. D., Tewari, T. P., Collis, W. J., Duveiller, E., Singh, P. K., Joshi, A. K., Singh, R. P., Braun, H. J., Peterson, G. L., Pedley, K. F., Farman, M. L., and Valent, B. 2016. First report of wheat blast caused by Magnaporthe oryzae pathotype Triticum in Bangladesh. Plant Dis. 100:2330.

Mehta, Y. R., Riede, C. R., Campos, L. A. C., and Kohli, M. M. 1992. Integrated management of major wheat diseases in Brazil: An example for the Southern Cone region of Latin America. Crop Prot. 11:517-524.
Molnár, I., Vrána, J., Burešová, V., Cápal, P., Farkas, A., Darkó, É., Cseh, A. Kubaláková, M., Molnár-Láng, M., and Doležel, J. 2016. Dissecting the $\mathrm{U}, \mathrm{M}, \mathrm{S}$ and $\mathrm{C}$ genomes of wild relatives of bread wheat (Aegilops spp.) nto chromosomes and exploring their synteny with wheat. Plant J. 88: 452-467.

Mottaleb, K. A., Singh, P. K., He, X., Hossain, A., Kruseman, G., and Erenstein, O. 2019. Alternative use of wheat land to implement a potential wheat holiday as wheat blast control: In search of feasible crops in Bangladesh. Land Use Policy 82:1-12.

Murakami, J., Tosa, Y., Kataoka, T., Tomita, R., Kawasaki, J., Chuma, I., Sesumi, Y., Kusaba, M., Nakayashiki, H., and Mayama, S. 2000. Analysis of host species specificity of Magnaporthe grisea toward wheat using a genetic cross between isolates from wheat and foxtail millet. Phytopathology 90:1060-1067.

Perelló, A., Martinez, I., and Molina, M. 2015. First report of virulence and effects of Magnaporthe oryzae isolates causing wheat blast in Argentina. Plant Dis. 99: 1177.

Tagle, A. G., Chuma, I., and Tosa, Y. 2015. Rmg7, a new gene for resistance to Triticum isolates of Pyricularia oryzae identified in tetraploid wheat Phytopathology 105:495-499.

Urashima, A. S., Grosso, C. R. F., Stabili, A., Freitas, E. G., Silva, C. P., Netto, D. C. S., Franco, I., and Bottan, J. H. M. 2009. Effect of Magnaporthe grisea on seed germination, yield and quality of wheat. Pages 267-277 in: Advances in Genetics, Genomics and Control of Rice Blast Disease. G.-L. Wang and B. Valent, eds. Springer, Dordrecht, The Netherlands.

Urashima, A. S., Lavorent, N. A., Goulart, A. C. P., and Mehta, Y. R. 2004 Resistance spectra of wheat cultivars and virulence diversity of Magnaporthe grisea isolates in Brazil. Fitopatol. Bras. 29:511-518.

Valent, B., Farrall, L., and Chumley, F. 1991. Magnaporthe grisea genes for pathogenicity and virulence identified through a series of backcrosses. Genetics 127:87-101.

Viedma, L. Q. 2005. Wheat blast occurrence in Paraguay. (Abstr.) Phytopathology 95:S152.

Wang, S., Asuke, S., Vy, T. T. P., Inoue, Y., Chuma, I., Win, J., Kato, K., and Tosa Y. 2018. A new resistance gene in combination with $R m g 8$ confers strong resistance against Triticum isolates of Pyricularia oryzae in a common wheat landrace. Phytopathology 108:1299-1306.

Warburton, M. L., Crossa, J., Franco, J., Kazi, M., Trethowan, R., Rajaram, S. Pfeiffer, W., Zhang, P., Dreisigacker, S., and Van Ginkel, M. 2006. Bringing wild relatives back into the family: Recovering genetic diversity in CIMMYT improved wheat germplasm. Euphytica 149:289-301.

Williamson, V. M., Thomas, V., Ferris, H., and Dubcovsky, J. 2013. An Aegilops ventricosa translocation confers resistance against root-knot nematodes to common wheat. Crop Sci. 53:1412-1418.

Yu, J., Holland, J. B., McMullen, M. D., and Buckler, E. S. 2008. Genetic design and statistical power of nested association mapping in maize. Genetics 178 539-551.

Zhang, N., Luo, J., Rossman, A. Y., Aoki, T., Chuma, I., Crous, P. W., Dean, R., de Vries, R. P., Donofrio, N., Hyde, K. D., Lebrun, M. H., Talbot, N. J., Tharreau, D., Tosa, Y., Valent, B., Wang, Z., and Xu, J. R. 2016. Generic names in Magnaporthales. IMA Fungus 7:155-159.

Zhang, P., Dundas, I. S., Xu, S. S., Friebe, B., McIntosh, R. A., and Raupp, W. J. 2017. Chromosome engineering techniques for targeted introgression of rust resistance from wild wheat relatives. Methods Mol. Biol. 1659:163-172. 